\title{
Obtaining of Winter Rye (Secale Cereale L. ssp. Cereale) Haploid Embryos through Hybridization with Maize (Zea Mays L.)
}

\author{
I. MARcińsKA*, I. CzyczyŁo-Mysza, E. SkrzyPeK, M. WARChOŁ, K. Zieliński and E. Dubas \\ Polish Academy of Sciences, The Franciszek Górski Institute of Plant Physiology, \\ Niezapominajek 21, 30-239 Cracow, Poland
}

(Received 28 March 2017;

Accepted 9 February 2018)

\begin{abstract}
The aim of this study was to determine the effect of selected factors on rye (Secale cereale L.) haploid embryo production by the wide crossing method. The study was performed on fifteen winter rye genotypes. This is the first time for rye when besides the genotype, on the enlargement of ovaries and haploid embryo production, such factors as: type of auxin analogues 2,4-dichlorophenoxyacetic acid (2,4-D), 3,6-dichloro-2-methoxybenzoic acid (dicamba) and 4-amino-3,5,6-trichloropyridine-2-carboxylic acid (picloram), and the time between florets emasculation and pollination were investigated. All factors had a significant impact on rye ovary enlargement, however the haploid embryo formation depended only on rye genotype, not on kind of auxin and days between emasculation to pollination. In total, twenty one haploid embryos were formed by six genotypes of fifteen tested. On average, $13.86 \%$ (after 2,4-D treatment) to $20.05 \%$ (after dicamba treatment) enlarged ovaries per emasculated florets were obtained. Most of the ovaries enlarged when florets were pollinated 4 and 6 days after emasculation. Most of the haploid embryos formed when florets were pollinated 6 days after emasculation. The obtained haploid embryos did not germinate.
\end{abstract}

Keywords auxin, haploid embryo, maize, rye, wide crossing

\section{Introduction}

Rye (Secale cereale L.) is one of the most important cereals in Eastern and Northern Europe. Despite numerous beneficial characteristics of rye, its annual production decreases successively, which correlates with the lack of progress in its breeding compared with other cereals like wheat and barley. Unfortunately, the classical breeding of rye is very difficult because of its high self-incompatibility and inbred depression. On the other hand, rye is known as a recalcitrant plant species in regard to the in vitro culture response, thus the application of biotechnological methods (e.g., doubled haploid (DH) production, genetic transformation or selection of plants with beneficial changes of agronomic traits) is highly limited (Hromada-Judycka 2010). DH technology has become key tool for plant breeding. Using these techniques, the speed and efficiency of plant improvement pro-

*Corresponding author; E-mail: i.marcinska@ifr-pan.edu.pl; Phone: +48-12-425-33-01;

Fax: +48-12-425-33-20 
cesses can be significantly enhanced (Rubtsova 2013). Several methods of DH production have been investigated in cereals, including microspore and/or anther culture (androgenesis), ovary and ovule culture (gynogenesis) as well as wide hybridization through interspecific crosses. Major advantages of DH lines compared to pedigree lines include: maximum genetic variance among lines and testcross performance from the first generation, reduced length of breeding cycle, perfect fulfillment of distinctness, uniformity, stable varietal status, reduced costs in maintenance breeding as well as increased efficiency in marker-assisted selection, gene introgression and gene stacking (Sserumaga et al. 2015).

For cereals, androgenesis is the most commonly applied DH system. Anther or isolated microspore cultures have been more favorable than other methods. The production of DHs in rye has not been as efficient as for barley or wheat. Although high regeneration rates of green plants have been achieved with some rye lines or cultivars, rye can still be considered a recalcitrant species (Tenhola-Roininen 2006). Pioneering work on rye doubled haploid production was carried out by Wenzel and Thomas (1974) and Zenkteler and Misiura (1974) and concentrated solely on anther culture. Callus, embryos and green plants have been produced by microspore culture of $F_{1}$ winter hybrid types of $S$. cereale L. $\times$ S. vavilovii Grossh (Thomas and Wenzel 1975). In the nineties, the first studies with rye anther culture and success in high green plant regeneration rate were reported by Flehinghaus-Roux et al. (1995) and by Immonen and Anttila (1996). Since the first studies on anther or microspore cultures of rye, callus induction and embryo formation as well as albino and green plant rates vary depending on the genotype, physiological stage of donor plant, stress treatments, developmental stage of microspore as well as medium and culture conditions (Deimling and Flehinghaus-Roux 1997; Immonen 1999; Immonen and Anttila 1999, 2000). Rakoczy-Trojanowska et al. (1997) have suggested that various genotypes could have different requirements with regard to plant growth regulators and no universal medium exists for different rye genotypes. Compared to barley and wheat, the development of an efficient androgenic cell culture system for rye is less advanced. Problems associated with rye anther and microspore culture include poor embryogenic callus induction, limited green plant regeneration, a high proportion of albinos and severe genotype dependency. More effective methods are needed to produce doubled haploids from a wide range of genotypes (Altpeter and Korzun 2007).

Wide crossing with pollen from another cereal genus (e.g., Hordeum bulbosum or Zea mays) is an alternative method of producing haploid embryos. This method involves fertilization, but foreign chromosomes are eliminated during early embryo development. Advantages of this approach are that the methods involved (emasculation, pollination, embryo culture) are familiar to breeders, cross combinations can be manipulated to maximize haploid embryo production by eliminating genotypic dependency on the maternal side (Forster et al. 2007). In the study of Zenkteler and Nitsche (1984), where Secale cereale was pollinated with Dactylis glomerata, Festuca glauca, Hordeum bulbosum and Zea mays, globular hybrid embryo production was achieved. Haploid embryos from rye $x$ maize crosses obtained by Laurie et al. (1990) died already at the early stages of development, while Deimling et al. (1994) and Altenhofer et al. (1997) observed conversion of 
rye embryos into plants. Ponitka and Ślusarkiewicz-Jarzina (2004), based on cleared ovule preparations, found irregularities in endosperm development. Usually the ovules contained both embryo and endosperm, but they sometimes contained embryos without endosperm or the endosperm alone. The developmental stage of such embryos for in vitro culture due to irregularities in endosperm development is the most common cause of dieback of haploid embryos obtained by the wide hybridization method. Similar results was observed for oat haploid embryos (Noga et al. 2016).

The aim of this study was to determine the effect of selected factors on rye (Secale cereale L.) haploid embryo production by the wide crossing method. The study was performed on fifteen Polish winter rye genotypes and investigated the importance of donor plant vernalization. Information that genotype, type of auxin and days between floret emasculation and pollination by maize on the efficiency of ovary enlargement and haploid embryo production could be helpful in optimization of rye doubled haploid production using this method.

\section{Materials and Methods}

Fifteen Polish $\mathrm{F}_{1}$ winter rye (Secale cereale L.) genotypes: 2550, 94, 41, 31, 61, S1123/14, S1138/14, 127-2R, 186-R, 131-R, 135-2R, 143-3R, S1131/14, 2545 and 36 were provided by Danko Plant Breeding Ltd. Rye grains were treated with fungicide Funaben $T$ (Synthos Agro Ltd., Poland) and placed in containers with perlite wetted with Hoagland medium (Hoagland and Arnon, 1938). Thus prepared seeds were vernalized for 7 and 9 weeks at $3 \pm 1{ }^{\circ} \mathrm{C}$ with an $8 \mathrm{~h}$ photoperiod under $100 \mu \mathrm{mol} \mathrm{m} \mathrm{m}^{-1}$ (PAR). After vernalization, five plants per genotype were planted individually to $3 \mathrm{dm}^{3}$ pots filled with a mixture of soil with sand $(3: 1 \mathrm{v} / \mathrm{v})$. Rye and maize plants were grown in a greenhouse in April and May, under controlled conditions, $800 \mu \mathrm{mol} \mathrm{m} \mathrm{m}^{-2} \mathrm{~s}^{-1}$ photosynthetic active radiation (PAR) and long day (16-h light, 8-h dark). Photoperiod and light intensity were maintained with the support of high pressure sodium lamps (400 W; Philips SON-T AGRO, Belgium) between 6-8 a.m., 6-10 p.m. and on cloudy days. Rye plants were grown at $21 / 17^{\circ} \mathrm{C}$ day/night.

Maize (Zea mays L. var. saccharata) cv. Waza used as a pollen donor, was grown in a greenhouse at $25-28 / 17^{\circ} \mathrm{C}$ day/night and the same light regime as rye. In order to synchronize the flowering of rye with pollen production by maize, maize seeds were sown for the first time about 3 weeks before the end of rye vernalization ( 7 or 9 weeks) and then 5 times at 7 day intervals.

All rye and maize plants were fertilized with a liquid medium once a week (Hoagland and Arnon 1938). Emasculation of rye florets was performed when the spikes remained prior to anthesis. Dependently of genotype 24 to 35 spikes were emasculated and covered with glassine bags. After 3-14 days spikes were pollinated with fresh maize pollen. Then, 1 day later rye pistils were treated with three different analogues of auxins: 2,4-dichlorophenoxyacetic acid (2,4-D), 3,6-dichloro-2-methoxybenzoic acid (dicamba) or 4-amino3,5,6-trichloropyridine-2-carboxylic acid (picloram) at a concentration of $100 \mathrm{mg} \mathrm{dm}^{-3}$. Two to 3 weeks later enlarged ovaries were isolated from the florets and surface-sterilized 
in $70 \% \mathrm{v} / \mathrm{v}$ ethanol $(1 \mathrm{~min}), 2.5 \% \mathrm{v} / \mathrm{v}$ calcium hypochlorite $(8 \mathrm{~min})$ and then washed four times with sterilized water. Embryos were isolated and placed on 190-2 medium (Zhuang and $\mathrm{Xu} 1983)$ with $9 \%(\mathrm{w} / \mathrm{v})$ maltose solidified with $0.6 \%(\mathrm{w} / \mathrm{v})$ agar. The $\mathrm{pH}$ of the medium was adjusted to 5.8 using $0.1 \mathrm{~N} \mathrm{NaOH}$ before autoclaving at $121^{\circ} \mathrm{C}$ for $20 \mathrm{~min}$. Embryos were maintained under $100-150 \mu \mathrm{mol} \mathrm{m} \mathrm{m}^{-1} \mathrm{PAR}$ at $21^{\circ} \mathrm{C}$ and a $16 \mathrm{~h}$ photoperiod. All reagents used in the experiment were obtained from Sigma-Aldrich.

The analysis of rye ovaries enlargement and embryo formation after maize pollination was performed depending on the genotype, type of auxin used to stimulate the ovary enlargement and time between floret emasculation and pollination.

\section{Statistical analysis}

The results concerning the influence of the aforementioned factors were evaluated using two way ANOVA variance analysis and Duncan's test incorporated in the statistical package STATISTICA 12.0 (Stat-Soft Inc., USA). Significant differences between traits depending on source of variation are marked by asterisks $(*, * * *$, significant at $p \leq 0.05$, 0.001 , respectively; ns - not significant). Mean values marked with the same letters do not differ significantly.

\section{Results}

To obtain the highest number of spikes per plant (even 11 spikes), vernalization should last over a period of 9 weeks (data not shown). Shorter vernalization (7 weeks) resulted in a lower number of heading spikes. In addition, to synchronize rye flowering with pollen production by maize, maize seeds should be sown for the first time approx. 3 weeks before the 9 weeks of vernalization and then 5 times at 7 day intervals. Rye needs approximately 60 days to reach appropriate stage of spike development for wide crossing (prior to anthesis). The analysis of variance showed significant differences in the efficiency of rye ovaries enlargement relative to the genotype, type of auxin and days between floret emasculation to pollination (Table 1). There were significant differences

Table 1. Analysis of variance showing the significance of genotype, type of auxin, days between florets emasculation to pollination on rye ovaries enlargement and haploid embryo production using the wide hybridization method

\begin{tabular}{|c|l|c|c|c|c|c|}
\hline \multicolumn{1}{|c|}{ Trait } & \multicolumn{1}{|c|}{ Source of variation } & SS & df & MS & F & p \\
\hline \multirow{3}{*}{$\begin{array}{l}\text { Enlarged } \\
\text { ovaries }\end{array}$} & Genotype & 4746.68 & 14 & 339.05 & 3.49 & $0.000^{* * *}$ \\
\cline { 2 - 7 } & Type of auxin & 545.82 & 2 & 272.91 & 2.62 & $0.049 *$ \\
\cline { 2 - 7 } & Days between emasculation to pollination & 4127.23 & 11 & 275.14 & 2.78 & $0.000^{* * *}$ \\
\hline \multirow{3}{*}{ Embryos } & Genotype & 5.43 & 14 & 0.38 & 2.02 & $0.015^{*}$ \\
\cline { 2 - 7 } & Type of auxin & 0.05 & 2 & 0.02 & 0.13 & $0.870^{\text {ns }}$ \\
\cline { 2 - 7 } & Days between emasculation to pollination & 1.06 & 11 & 0.07 & 0.34 & $0.989^{\text {ns }}$ \\
\hline
\end{tabular}

SS sum of squares; df degrees of freedom; MS mean squares; ns not significant; *, ***, significant at $\mathrm{p} \leq 0.05,0.001$, respectively. 
among genotypes in the haploid embryo formation, in contrast to the type of auxin and days between floret emasculation to pollination. Overall, 435 rye spikes (17154 florets) from all genotypes were emasculated and pollinated with maize. Approximately two weeks after pollination, 2838 ovaries had been enlarged (Table 2).

Enlarged ovaries were more than twice bigger than the ovaries before pollination and non-enlarged ones (Fig. 1A, B and C). There was an average of $16.50 \%$ enlarged ovaries per pollinated floret. The highest number of enlarged ovaries per emasculated floret were observed in genotypes S1138/14, S1131/14, 2550 and 186-R $(34.27 \%, 26.81 \%, 25.76 \%$, $25.57 \%$, respectively), whereas the lowest $(3.82 \%)$ in genotype 61 . In total, 21 haploid embryos (Fig. 1D) were formed by six genotypes of 15 tested. The highest number of haploid embryos, 12 (1.17\% per emasculated floret), were obtained from genotype 2545, while genotype 2550 formed 4 haploid embryos ( $0.28 \%$ per emasculated floret), genotype 41,2 embryos ( $0.16 \%$ per emasculated floret), and genotypes $127-2 \mathrm{R}, 31,186-\mathrm{R}$ only 1 embryo $(0.11 \%, 0.09 \%, 0.07 \%$ per emasculated floret, respectively). The obtained haploid embryos did not germinate and convert into plants on the investigated 190-2 medium. The number of enlarged rye ovaries and haploid embryo formation depended on the time between emasculation of rye florets and pollination by maize. Ovary enlargement was observed in all the investigated time periods, however, most of them enlarged when florets were pollinated 4-11 days after emasculation (Fig. 2). In turn, haploid embryos

Table 2. The effect of rye genotype on the efficiency of rye haploid embryos production

\begin{tabular}{|c|c|c|c|c|c|c|}
\hline \multirow{2}{*}{ Genotype } & \multicolumn{4}{|c|}{ Number of } & \multirow{2}{*}{$\begin{array}{l}\text { Enlarged ovaries/ } \\
\text { pollinated florets } \\
{[\%]}\end{array}$} & \multirow{2}{*}{$\begin{array}{c}\text { Haploid embryos } \\
\text { pollinated florets } \\
{[\%]}\end{array}$} \\
\hline & $\begin{array}{l}\text { Emasculated } \\
\text { spikes }\end{array}$ & $\begin{array}{l}\text { Pollinated } \\
\text { florets }\end{array}$ & $\begin{array}{c}\text { Enlarged } \\
\text { ovaries }\end{array}$ & $\begin{array}{l}\text { Haploid } \\
\text { embryos }\end{array}$ & & \\
\hline 2550 & 35 & 1435 & 360 & 4 & 25.76 & 0.28 \\
\hline 94 & 24 & 1008 & 88 & 0 & 8.73 & 0.00 \\
\hline 41 & 32 & 1248 & 209 & 2 & 16.75 & 0.16 \\
\hline 31 & 28 & 1120 & 143 & 1 & 12.77 & 0.09 \\
\hline 61 & 31 & 1178 & 45 & 0 & 3.82 & 0.00 \\
\hline S1123/14 & 25 & 1050 & 87 & 0 & 8.29 & 0.00 \\
\hline $\mathrm{S} 1138 / 14$ & 28 & 1036 & 355 & 0 & 34.27 & 0.00 \\
\hline $127-2 \mathrm{R}$ & 26 & 936 & 173 & 1 & 18.48 & 0.11 \\
\hline 186-R & 35 & 1365 & 349 & 1 & 25.57 & 0.07 \\
\hline $131-R$ & 28 & 1148 & 103 & 0 & 8.97 & 0.00 \\
\hline $135-2 \mathrm{R}$ & 26 & 988 & 178 & 0 & 18.02 & 0.00 \\
\hline $143-3 R$ & 28 & 1092 & 168 & 0 & 15.38 & 0.00 \\
\hline $\mathrm{S} 1131 / 14$ & 29 & 1160 & 311 & 0 & 26.81 & 0.00 \\
\hline 2545 & 25 & 1025 & 197 & 12 & 19.22 & 1.17 \\
\hline 36 & 35 & 1365 & 72 & 0 & 5.27 & 0.00 \\
\hline Total/Average & 435 & 17154 & 2838 & 21 & 16.50 & 0.13 \\
\hline
\end{tabular}



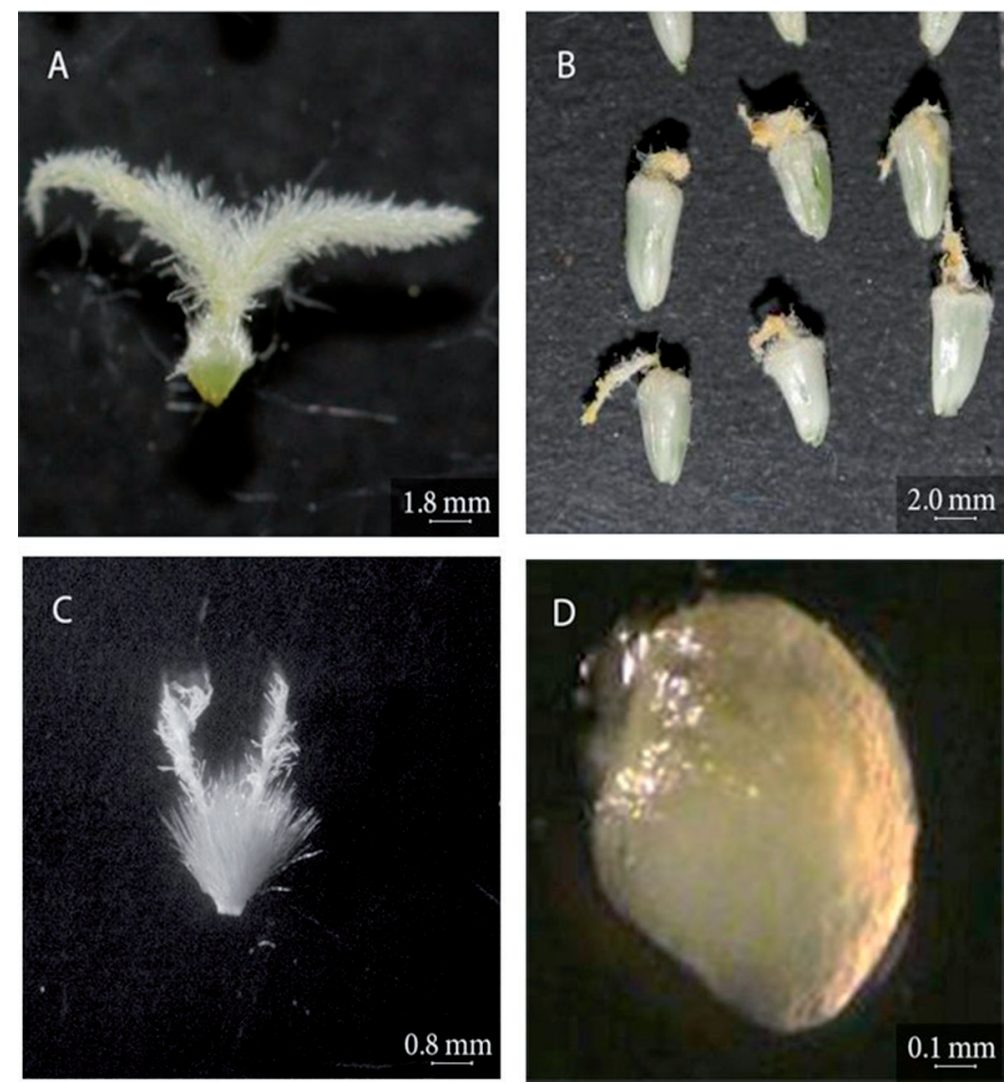

Figure 1. Rye $\times$ maize wide crossing for haploid embryo production: A ovary before pollination; B enlarged ovaries after treatment with dicamba; $\mathbf{C}$ not enlarged ovary after treatment with dicamba; $\mathbf{D}$ haploid embryo

formed only when florets were pollinated 5-10 days after emasculation (Fig. 3). The highest percentage of enlarged ovaries per emasculated floret was $25.36 \%$ and $26.87 \%$, respectively (Fig. 2).

The lowest ovary enlargement was observed when they were pollinated by maize 13 $(5.26 \%)$ and 14 days after emasculation (2.56\%). The highest percentage of enlarged ovaries not always resulted in the highest percentage of haploid embryo formation. When florets were pollinated 6 days after emasculation, $26.87 \%$ of enlarged ovaries formed 13 haploid embryos ( $0.33 \%$ per emasculated florets) (Fig. 3$)$. Despite the $25.36 \%$ of enlarged ovaries when florets were pollinated 4 days after emasculation, haploid embryo formation was not observed. The number of enlarged ovaries was affected by the type of auxin and genotype (Table 3). The average number of enlarged ovaries per emasculated floret after dicamba treatment was $20.05 \%$, while in the case of picloram and 2,4-D it was $16.01 \%$ and $13.86 \%$, respectively. 


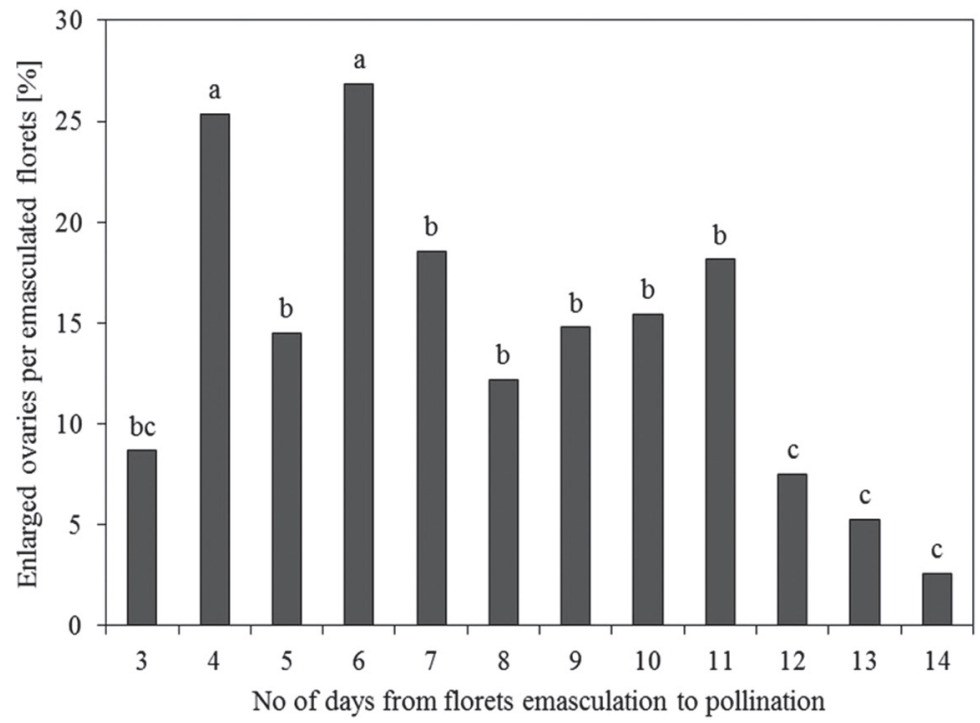

Figure 2. The influence of the number of days between emasculation of rye florets and pollination with maize on the percent of enlarged ovaries per emasculated florets independently on genotype. Mean values marked with the same letters do not differ significantly according to Duncan test at $\mathrm{p} \leq 0.05$

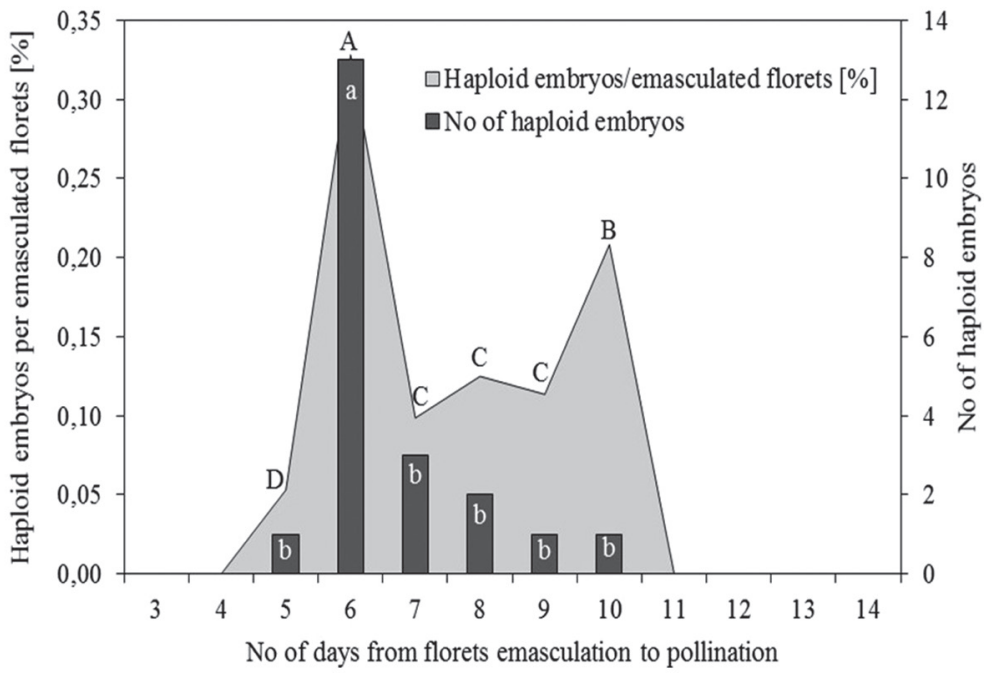

Figure 3. The influence of the number of days between emasculation of rye florets and pollination with maize on the number of haploid embryos formation and the percent of haploid embryos per emasculated florets independently on genotype. Mean values marked with the same letters do not differ significantly (A-D - the number of haploid embryos; $\mathrm{a}-\mathrm{b}$ - the percent of haploid embryos per emasculated florets) according to Duncan test at $\mathrm{p} \leq 0.05$ 
Table 3. The effect of auxin on the number of enlarged ovaries and haploid embryos per pollinated florets [\%] dependently on rye genotype.

Mean values marked with the same letters do not differ significantly according to Duncan test $(\mathrm{p} \leq 0.05)$

\begin{tabular}{|c|c|c|c|c|c|c|}
\hline \multirow{2}{*}{ Genotype } & \multicolumn{3}{|c|}{ Enlarged ovaries per pollinated florets [\%] } & \multicolumn{3}{|c|}{ Haploid embryos per pollinated florets [\%] } \\
\hline & 2,4-D & Dicamba & Picloram & 2,4-D & Dicamba & Picloram \\
\hline 2550 & 30.82 & 20.16 & 26.29 & 0.67 & 0.00 & 0.27 \\
\hline 94 & 2.38 & 18.03 & 7.74 & 0.00 & 0.00 & 0.00 \\
\hline 41 & 3.85 & 17.31 & 23.59 & 0.00 & 0.32 & 0.00 \\
\hline 31 & 15.42 & 16.88 & 4.69 & 0.00 & 0.00 & 0.31 \\
\hline 61 & 0.00 & 7.89 & 2.37 & 0.00 & 0.00 & 0.00 \\
\hline S1123/14 & 5.95 & 8.33 & 13.81 & 0.00 & 0.00 & 0.00 \\
\hline $\mathrm{S} 1138 / 14$ & 44.79 & 21.62 & 37.61 & 0.00 & 0.00 & 0.00 \\
\hline $127-2 \mathrm{R}$ & 23.26 & 15.28 & 17.22 & 0.35 & 0.00 & 0.00 \\
\hline $186-\mathrm{R}$ & 10.43 & 40.51 & 33.33 & 0.17 & 0.00 & 0.00 \\
\hline $131-R$ & 2.93 & 19.51 & 7.76 & 0.00 & 0.00 & 0.00 \\
\hline $135-2 R$ & 28.16 & 22.18 & 3.51 & 0.00 & 0.00 & 0.00 \\
\hline $143-3 R$ & 10.62 & 20.09 & 12.82 & 0.00 & 0.00 & 0.00 \\
\hline $\mathrm{S} 1131 / 14$ & 19.25 & 30.91 & 30.63 & 0.00 & 0.00 & 0.00 \\
\hline 2545 & 5.23 & 37.67 & 11.65 & 0.00 & 1.90 & 1.36 \\
\hline 36 & 4.81 & 4.36 & 7.12 & 0.00 & 0.00 & 0.00 \\
\hline Average & 13.86 & 20.05 & 16.01 & 0.08 & 0.15 & 0.13 \\
\hline
\end{tabular}

The highest number of enlarged ovaries per emasculated floret after 2,4-D treatment was obtained in two genotypes: S1138/14 and 2550 (44.79\% and 30.82\% respectively), after dicamba treatment in three genotypes: 186-R, 2545 and S1131/14 (40.51\%, 37.67\% and $30.91 \%$ respectively), and after picloram in three genotypes S1138/14, 186-R and $\mathrm{S} 1131 / 14$ (37.61\%, 33.33\% and 30.63\% respectively). Genotype 61 was the least responsive one, as after 2,4-D treatment the ovaries did not even enlarge. The highest frequency of haploid embryo production was recorded after dicamba treatment $(0.15 \%)$, then after picloram and 2,4-D (0.13\% and $0.08 \%$, respectively). Dicamba caused the highest haploid embryo formation in genotype 2545 (1.19\%). The same genotype formed $1.36 \%$ of haploid embryos after picloram. The frequency of haploid embryos in other genotypes ranged from $0.67 \%$ to $0.17 \%$ depending on auxin treatment.

\section{Discussion}

Tissue culture methods can effectively improve the breeding of rye. However, their application is highly limited by the absence of efficient procedures for plant regeneration in vitro, because rye is one of the most recalcitrant cereals with regard to the tissue culture 
response, and successful regeneration is highly dependent on the genotype (Targońska et al. 2013). Alternatively, substantial changes to centromeric histone H3 (CENH3), such as replacing the hypervariable N-terminal tail of CENH3 with the tail of conventional histone H3 and fusing it to GFP (producing "tailswap-cenh3"), or complementing the cenh3.2-null mutant with homologs from the mustard family CENH3s creates haploid inducer lines in the model plant Arabidopsis thaliana. Haploidization occurred only when such a haploid inducer was crossed with a wild-type plant. The haploid inducer line proved to be stable upon selfing, suggesting that competition between modified and wildtype centromeres in the developing hybrid embryo results in the inactivation of the centromeres from the inducer parent. Consequently, chromosomes from the inducer parent are lost, and progeny can be recovered that retain only the haploid chromosome set of the wild-type parent (Karimi-Ashtiyani et al. 2015). CENH3 is almost universal in eukaryotes, so this method has the potential to produce haploids in any plant species.

Some in vitro techniques (ovary, anther, and microspore culture) appear to be more promising than traditional breeding techniques. Hybridization involving interspecific and intergeneric crosses encounters numerous obstacles, mainly concerning pre- and postzygotic barriers (Rybczyński 1990). Rye wide hybridization and the utilization of ovary or embryo culture for rye doubled haploid (DH) production have either never been investigated or their failures have not been published.

In contrast, anther and microspore cultures have been the subject of several studies over the past 40 years (Wenzel and Thomas 1974; Thomas and Wenzel 1975, Wenzel et al. 1977; Flechinghaus et al. 1991; Flechinghaus-Roux et al. 1995; Immonen 1999; Immonen and Anttila 1996, 1999, 2000; Rakoczy-Trojanowska et al. 1997; Guo and Pulli 2000; Ma et al. 2004; Mikołajczyk et al. 2012). Most of all, the authors identified basal media composition that enhanced haploid embryo induction and green plant regeneration. However, a problem in this technique is the formation of numerous chlorophyll-deficient plantlets and very low regeneration efficiency. Survival and response of the microspores have been maximized by growing the plants used as a source of androgenic cultures under optimal conditions (Hörlein 1991). Vernalization period of the donor plants is important for regeneration of androgenic plants. Best anther culture response has been observed after plants were vernalized at $2{ }^{\circ} \mathrm{C}$ for 8 to 14 weeks with an optimum at 10 weeks (Flehinghaus et al. 1991). Vernalization for less than 8 weeks resulted in donor plants with small number of spikes and did not develop. Different genotypes require distinct lengths of vernalization, but in general, longer duration treatments are advised (Deimling and Flehinghaus-Roux 1997). Also in our investigation, longer time of vernalization (9 weeks compared to 7 weeks) resulted in a higher spike production and plants were in a better condition.

Zenkteler and Nitsche (1984) reported that wide hybridization in cereals resulted in the globular hybrid embryo when Secale cereale, Hordeum vulgare and Triticum aestivum were used as female species in crosses with 15 different species of Gramineae. The embryos were present in embryo sacs of $S$. cereale pollinated with: Dactylis glomerata, Festuca glauca, Hordeum bulbosum and Zea mays. In all these cases, globular embryos were formed, however, they degenerated six to ten days after pollination. The endosperm 
was very poorly, if at all, developed. In crosses of Secale cereale with Hordeum bulbosum or Zea mays, endosperm development often appeared normal without embryos. Nevertheless, endosperm development collapsed in all cases before the tenth day after pollination. Using interspecific pollination of rye with maize pollen, Laurie et al. (1990) observed that when the rye variety Petkus Spring was pollinated with Seneca 60, fertilization occurred in $18.7 \%$ of the florets studied. Most fertilized florets had both embryo and endosperm and preliminary studies indicated that the elimination of maize chromosomes occurred early in the development of the embryo and endosperm. Based on cleared ovule preparations, the development of the embryo and endosperm was observed at 48, 72 and $96 \mathrm{~h}$ after pollination. Embryos were formed in eight cross combinations (3.3\% to $23.3 \%$ of embryos per ovules depending on rye genotype), but in five combinations the ovules had both embryo and endosperm nuclei. In a sample of 344 cleared ovules, $28(8.1 \%)$ had both embryo and endosperm, 15 (4.4\%) had only embryo, and $13(3.8 \%)$ had only endosperm (Ponitka and Ślusarkiewicz-Jarzina 2004). In our study, haploid embryos were formed in six genotypes from fifteen tested and ovary enlargement varied from $34.27 \%$ to $3.82 \%$ depending on the genotype. Moreover, as in the cited works, ovules in the current study had no endosperm irrespective whether they formed embryos or not.

Zenkteler and Nitzsche (1984) observed that none of the investigated cereal crosses seemed to fulfill the conditions necessary for haploid production. Independently of the detected haploid cells, the frequency of haploid embryo formation was too low for practical application. On the other hand, Zenkteler and Nitzsche (1984) stated that the formation of hybrid embryos offered new possibilities for intergeneric hybridization and gene transfer. There are certainly problems with embryo culture techniques concerning extremely young embryos, but they should be overcome in the near future. Using the wide crossing technique, Deimling et al. (1994) obtained six embryos, from which two DH lines were obtained after pollination of 48,000 emasculated flowers. One was induced after pollination with pearl millet, the other with maize. The effort required to emasculate and pollinate such a large number of rye flowers to regenerate so few haploids is far too great for interspecific pollination to be a suitable haploidization technique in rye. In our study, from 17,154 pollinated florets 21 haploid embryos were formed, but they did not germinate and convert into plants. Tenhola-Roininen et al. (2006) reported that due to the low survival rate of green regenerants (36-61\%) and low fertility (3-29\%), only about $10-36 \%$ of all the regenerated plants would have been suitable for rye research or for breeding purposes.

\section{Conclusions}

The development of DHs is more problematic in out-crossing self-pollinating species. The above results clearly showed that wide hybridization between taxonomically diverse cereal crops could be achieved, but such observations would be of limited interest if plants could not be produced. In all of the crosses, it has proved very difficult to recover plants using conventional embryo rescue techniques. As mentioned by Zenkteler and Nitzsche (1984), the reasons for this are still not known, but it is probably caused by the 
absence or poor development of the endosperm. Admittedly, some rye haploid embryos and few plants have been obtained by wide crossing, but the embryo rescue method is still necessary.

\section{Acknowledgments}

The research was supported by the individual National Project HOR hn-801-PB-8/16 financed by the Ministry of Agriculture and Rural Development and by the IPP PAS statute project $\mathrm{T} 1 \mathrm{Zb} 1 / 2016$.

\section{References}

Altpeter, F., Korzun, V. 2007. Rye. In: Pua, E.C., Davey, M.R. (eds) Biotechnology in Agriculture and Forestry, Transgenic Crops IV, vol. 59 Springer-Verlag, Berlin Heidelberg, pp. 107-117.

Altenhofer, P., Oertel, C., Matzk, F. 1997. Chromosome elimination in wide crosses of Poaceae. Current topics in plant cytogenetics related to plant improvement. International Symposium held at Tulln, Austria, February 21-22, pp. 310-317.

Deimling, S., Flehinghaus-Roux, T., Rober, F., Schechert, A., Roux, S.R., Geiger, H.H. 1994. Doubled haploid production-now reproducible in rye. In: Abstracts VIIIth International Congress of Plant Tissue and Cell Culture, Firenze, June 12-17, p. 95.

Deimling, S., Flehinghaus-Roux, T. 1997. Haploidy in rye. In: Jain, M.S., Sopory, S.K.,Veilleux, R.E. (eds) In Vitro Haploid Production in Higher Plants. Kluwer Academic Publishers, Dordrecht, pp. 181-204.

Flehinghaus, T., Deimling, S., Geiger, H.H. 1991. Methodical improvements in rye anther culture. Plant Cell Rep. 10:397-400.

Flehinghaus-Roux, T., Deimling, S., Geiger, H.H. 1995. Anther culture ability in Secale cereale L. Plant Breed. 114:259-261.

Forster, B.P., Heberle-Bors, E., Kasha, K.J., Touraev, A. 2007. The resurgence of haploids in higher plants. Trends Plant Sci. 12:368-375.

Guo, Y.D., Pulli, S. 2000. Isolated microspore culture and plant regeneration in rye (Secale cereale L.). Plant Cell Rep. 19:875-880.

Hoagland, D.R., Arnon, D.I. 1938. A water culture method for growing plants without soil. Circ. Univ. Calif., Agric. Exp. Stn., No. 347.

Hörlein, A.J. 1991. Metodische Untersuchungen zur Antherenkultur bei Roggen. Metodische Untersuchungen zur Antherenkultur bei Roggen. Dissertation zur Erlagung des Grades eines Doktors der Agrarwissenschaften, Universität Hohenheim, Stuttgart.

Hromada-Judycka, A., Bolibok-Brągoszewska, H., Rakoczy-Trojanowska, M. 2010. Genetically directed differential subtraction chain products related to in vitro response of immature embryos of rye (Secale cereale L.): isolation, characterization, and expression analysis Plant Cell Tiss. Org. Cult. 100:131-138.

Immonen, S. 1999. Androgenetic green plants from winter rye, Secale cereale L., of diverse origin. Plant Breeding 118:319-322.

Immonen, S., Anttila, H. 1996. Success in anther culture of tye. Proc. EUCARPIA Int. Symp. Rye Breeding \& Genetics. Vortr. Pflanzenziichtg. 35:237-244.

Immonen, S., Anttila, H. 1999. Cold pretreatment to enhance green plant regeneration from rye anther culture. Plant Cell Tiss. Org. Cult. 57:121-127.

Immonen, S., Anttila, H. 2000. Media composition and anther plating for production of androgenetic green plants from cultivated rye (Secale cereale L.). J. Plant Physiol. 156:204-210.

Karimi-Ashtiyani, R., Ishii, T., Niessen, M., Stein, N., Heckmann, S., Gurushidze, M. 2015. Point mutation impairs centromeric CENH3 loading and induces haploid plants. Proc. Natl. Acad. Sci. U.S.A. 112:1121111216. 
Laurie, D.A., O’Donoughue, LS., Bennett, M.D. 1990. Wheat $\times$ maize and other wide sexual hybrids: their potential for genetic manipulation and crop improvement. In: Gustafson, J.P. (ed.), Genetic manipulation in plant improvement II, Plenum Press, New York, pp. 95-126.

Ma, R., Guo, Y., Pulli, S. 2004. Comparison of anther and microspore culture in the embryogenesis and regeneration of rye. Plant Cell Tiss. Org. Cult. 76:147-157.

Mikołajczyk, S., Broda, Z., Weight, D. 2012. The effect of cold temperature stress on the viability of rye (Secale cereale L.) microspores. J. Biotech. 93(2):139-142.

Noga A., Skrzypek, E., Warchoł, M., Czyczyło-Mysza, I., Dziurka, K., Marcińska, I., Juzoń, K., Warzecha, T., Sutkowska, A., Nita, Z., Werwińska, K. 2016. Conversion of oat (Avena sativa L.) haploid embryos into plants in relation to embryo developmental stage and regeneration media. In Vitro Cellular \& Developmental Biology - Plant 52:590-597.

Ponitka, A., Ślusarkiewicz-Jarzina, A. 2004. Cleared-ovule technique used for rapid access to elary embryo development in Secale cereale x Zea mays crosses. Acta Biol. Cracov. Series Botanica 46:133-137.

Rakoczy-Trojanowska, M., Smiech, M., Malepszy, S. 1997. The influence of genotype and medium on rye (Secale cereale L.) anther culture. Plant Cell Tiss. Org. Cult. 48:15-21.

Rubtsova, M., Gnad, H., Melzer, M., Weyen, J., Gils, M. 2013. The auxins centrophenoxine and 2,4-D differ in their effects on non-directly induced chromosome doubling in anther culture of wheat (T. aestivum L.) Plant Biotechnol. Rep. 7:247-255.

Rybczyński, J.J. 1990. Plant tissue culture of Secale: A review. Euphytica 46:57-70.

Sserumaga, J.P., Oikeh, S.O., Mugo, S., Asea, G., Otim, M., Beyene, Y., Abalo, G., Kikafunda, J. 2015. Genotype by environment interactions and agronomic performance of doubled haploids testcross maize (Zea mays L.) hybrids. Euphytica 207:353-365.

Tenhola-Roininen, T., Immonen, S., Tanhuanpää, P. 2006. Rye doubled haploids as a research and breeding tool - a practical point of view. Plant Breed. 125:584-590.

Targońska, M., Hromada-Judycka, A., Bolibok-Brągoszewska, H., Rakoczy-Trojanowska, M. 2013. The specificity and genetic background of the rye (Secale cereale L.) tissue culture response. Plant Cell. Rep. 32(1): $1-9$.

Thomas, E., Wenzel, G. 1975. Embryogenesis from microspores of rye. Naturwissenschaften 62:40-41.

Wenzel, G., Thomas, E. 1974. Observations on the growth in culture of anthers of Secale cereale. Z. Pflanzenzüchtg. 72:89-94.

Wenzel, G., Hoffmann, E., Thomas, E. 1977. Increased induction and chromosome doubling of androgenetic haploid rye. Theor. Appl. Genet. 5:81-86.

Zenkteler, M., Misiura, E. 1974. Induction of androgenic embryos from cultured anthers of Hordeum, Secale, and Festuca. Biochem. Physiol. Pflanzen. 165:337-340.

Zenkteler, M., Nitzsche, W. 1984. Wide hybridization experiment in cereals. Theor. Appl. Genet. 68:311-315.

Zhuang, J.J., Xu, J. 1983. Increasing differentiation frequencies in wheat pollen callus. In: Hu, H., Vega, M.R. (eds) Cell and Tissue Culture Techniques for Cereal Crop Improvement, Science Press, Beijing, p. 431 . 